\title{
AOIR
}

Selected Papers of \#AoIR2021:

The 22nd Annual Conference of the

Association of Internet Researchers

Virtual Event / 13-16 Oct 2021

\section{END-USER FLEXIBILITIES IN CONTEMPORARY DIGITAL COPYRIGHT LAW - AN EMPIRICAL ANALYSIS OF END-USER LICENSE AGREEMENTS}

\author{
Péter Mezei \\ University of Szeged \\ István Harkai \\ University of Szeged
}

In the platform age, copyright protected contents are primarily disseminated over the internet. This model poses various challenges to the copyright regime that was mainly designed in and for the analogue age. One of these challenges is related to the fair balance between the interests of rightholders and other members of the society. Copyright norms try to guarantee the high level of protection of rightholders and preserve some flexibility for the benefit of end-users. These flexibilities range from statutory limitations and exceptions (e.g., private use); resales (covered by the doctrine of exhaustion); or complaint-and-redress mechanisms. Platforms, with their private norms, especially end-user license agreements (EULAs), might effectively enforce that balance in their role as intermediaries in the chain of (e-)commerce.

The academic literature of end-user flexibilities is limited. Liliia Oprysk and Karin Sein have focussed on EULAs and end-user flexibilities from a consumer protection law perspective (Oprysk \& Sein, 2020). Pascale Chapdelaine has dealt with user rights and the contractual basis of different online uses (Chapdelaine, 2017). Other than these and a few more sources, we noticed a hiatus of comprehensive analysis of the interplay between end-user flexibilities and private ordering mechanisms in the digital copyright ecosystem. Hence, in our research, conducted within the frames of the reCreating Europe $\mathrm{H} 2020$ project, we focused on how private norms allow for or diminish the exercise of end-user flexibilities related to copyright protected subject matter. The paper first elaborates the pursued objectives, scope, considerations on comparability, and analytical steps. It continues with the comparative and empirical analysis of EULAs.

Suggested Citation (APA): Mezei, P., and Harkai, I., (2021, October). End-User Flexibilities in Contemporary Digital Copyright Law - An Empirical Analysis of End-User License Agreements. Paper presented at AolR 2021: The 22nd Annual Conference of the Association of Internet Researchers. Virtual Event: AolR. Retrieved from http://spir.aoir.org. 
Our methodology combines systematic, qualitative, and comparative analysis. A comparative research might focus on macro-, meso- or micro-level research questions (Van Hoecke, 2015: 21-22; Wolff, 2019: 491-492). Our study covers a meso-level research topic: studying online intermediaries' private ordering mechanisms. The goal of our research, as it is often the case in the comparative legal scholarship (Glenn, 2006: 57-65; Wolff, 2019: 491), was to pursue the enhancement of the learning and knowledge about the selected topic, and offer an insight into and form recommendations related to the private ordering mechanisms. Such recommendations are timely in light of the European Union's Copyright in the Digital Single Market (CDSM) Directive. Article 17(9) requires the implementation of various rules related to end-user flexibilities. Therefore, our research is also capable to introduce the pre-CDSM implementation state of the art of end-user flexibilities.

With respect to the actual methodology, we relied on Mark van Hoecke's "toolbox", rather than a fixed methodological roadmap (van Hoecke, 2015). Among the various methods included in van Hoecke's comparative legal research "toolbox", our study emphasizes the functional (van Hoecke, 2015: 9; Zweigert \& Kötz, 1996), contextual (van Hoecke, 2015: 16-18), and, consequently, the common core (Van Hoecke, 2015: $21)$ methods. They were complemented by empirical research tools. These allowed us to look at the practical functioning of the studied EULAs.

The proper selection of online intermediaries was a key element of our research. The main criteria followed in the selection of the analysed platforms have been (i) a certain level of development (predominantly web 2.0 models, i.e., models where end user involvement is not only necessary but inevitable), and (ii) similar, or almost similar, functions (mainly, hosting, streaming and/or selling of protected works or subject matter via the platform primarily by rights holders and/or end-users). Prima facie infringing, piratical or rogue websites were excluded. Further relevant factors were the general availability of the selected platforms in the EU, and the availability of English language versions of their EULAs. Furthermore, a "coincidence factor" was also taken into account: we were focusing on platforms that we are generally familiar with; have broad relevance (i.e., serve great number of users); and many of which fit into the recently introduced concept of "online content-sharing service providers" (OCSSPs) under Article 17 of the CDSM Directive. Niche platforms are not covered. In sum, twenty platforms were selected, including streaming sites with (e.g., YouTube, Twitch) or without (e.g., Spotify, Netflix) host function for end-users; online video game stores and other online marketplaces (e.g., Steam, Amazon); and social media platforms (e.g., Facebook, Twitter). The initial plan was to provide for an overview of the relevant rules, and the quantitative and qualitative analysis of these rules from the point of view of endusers.

At first, an extensive chart was created that contains excerpts from the EULAs of the studied platforms related to fifteen different variables. Following this initial data collection, our focus was directed at certain comparable aspects: (i) the license that end-users are granted; (ii) restricted acts that users are not entitled to perform; (iii) provisions, if any, on user-generated content (UGC); (iv) procedural safeguards and termination/modification of user account/subscription; ( $v$ ) other provisions, if applicable. The platforms, classified according to six different types of business models, were 
measured according to a "user-flexibility index". This scale starts with 1 (least flexible) and goes up to 5 (most flexible). To get a final value, seven different contributing factors were taken into consideration, such as the extent of access rights, the restricted uses, allowance of UGC, other technological restrictions on access (e.g., geo-blocking or other technology-related restrictions beyond the broadly defined set of restrictions that prohibit users to perform certain acts) or family sharing. Each aspect was graded separately, and the average of independent grades provided for the final score of the platform in the user flexibility index.

Our interim conclusion indicates that platforms that host mainly or also UGC reached a higher user-flexibility score, while platforms that provide only access to the protected subject matter, without any possibility to interact over the platform or create permanent copies of contents, scored less. This conclusion is partially due the fact that existing public norms on various end-user flexibilities have closer relevance for UGC-related platforms (regulatory lock-in effect), and to the fierce competition that necessitates such platforms to offer for more competitive and hence more user-friendly services (platform flexibility effect). On the other hand, platforms that offer mainly one-way streaming services coupled occasionally with a license of limited offline uses impose stronger limits on end-user access rights. That is mainly due to the different licensing schemes; and their selected business model, including their goal to build and monetize an allencompassing, wide repertoire of professional contents.

\section{References}

Chapdelaine, Pascale: Copyright User Rights - Contracts and the Erosion of Property, Oxford University Press, Oxford, UK, 2017

Glenn, H. Patrick: The Aims of Comparative Law. In Jan M. Smits (Ed.): Elgar Encyclopedia of Comparative Law, Edward Elgar, Cheltenham, 2006, p. 57-65.

Oprysk, Liliia, and Karin Sein: Limitations in End-User Licensing Agreements: Is There a Lack of Conformity Under the Digital Content Directive?, IIC - International Review of Intellectual Property and Competition Law, 5/2020, p. 594-623.

Van Hoecke, Mark: Methodology of Comparative Legal Research, Law and Method, 2015, p. 1-35.

Wolff, Lutz-Christian: Artificial Intelligence ante portas: The End of Comparative Law?, The Chinese Journal of Comparative Law, 3/2019, p. 484-504.

Zweigert, Konrad, and Hein Kötz: Einführung in die Rechtsvergleichung, Dritte Auflage, J. C. B. Mohr (Paul Siebeck), Tübingen, 1996 